\title{
Nitric oxide metabolites (nitrite and nitrate) in several clinical condition
}

\author{
G. Caimi*, E. Hopps, M. Montana, C. Carollo, V. Calandrino, E. Incalcaterra, B. Canino and \\ R. Lo Presti \\ Dipartimento Biomedico di Medicina Interna e Specialistica, Università di Palermo, Palermo, Italy
}

\begin{abstract}
We determined the concentration of nitric oxide metabolites $\left(\mathrm{NO}_{2}{ }^{-}+\mathrm{NO}_{3}{ }^{-}\right)$, expressed as $\mathrm{NOx}$, in several clinical conditions. Regarding this, we have examined 25 subjects with arterial hypertension, 41 subjects with chronic kidney disease in conservative treatment, 106 subjects with metabolic syndrome subdivided according to the presence $(n=43)$ or not $(n=63)$ of diabetes mellitus, 48 subjects with obstructive sleep apnea syndrome (OSAS), 14 women with systemic sclerosis complicated with Raynaud's phenomenon, 42 dialyzed subjects and 105 young subjects with acute myocardial infarction (AMI). In subjects with arterial hypertension, chronic kidney disease, metabolic syndrome, systemic sclerosis, as well as, in dialyzed and AMI subjects, we found at baseline a NOx increase. In dyalized subjects after a standard dialysis session, we observed a decrease in NOx. The increase in NOx in juvenile AMI was significantly influenced by cigarette smoking and less by cardiovascular risk factors and the extent of coronary lesions; at 3 and 12 months later than the initial event, we observed a decrease of NOx that remains significantly higher than the control group. In subjects with OSAS no difference in NOx was noted in comparison with normal controls, although their subdivision according to the apnea/hypopnea index operates a clear distinction regarding NOx concentration.
\end{abstract}

Keywords:

\section{Introduction}

Even if, at baseline, the main origin of plasma nitric oxide (NO) seems to be related to endothelial nitric oxide synthase (eNOS), in several clinical conditions the inducible NOS (iNOS) is hyperactivated and this event is especially associated with the increase of cytokines such as TNF $\alpha$, IL-1 $\beta$ and interferon $[29,56,75]$. As it is known NO is produced through the oxidation of L-arginine in different cells by a family of enzymes, the nitric oxide synthases, subdivided in three major classes: neuronal-NOS (nNOS, type 1), inducible-NOS (iNOS, type II) and endothelial-NOS (eNOS, type III). Each isoform is encoded on a different chromosome: the nNOS is encoded on chromosome 12, the iNOS on chromosome 17 while the eNOS on chromosome 7. The biological activity of each isoform depends on different conditions, in fact the synthesis and activity of eNOS and nNOS requires calcium and calmodulin while the iNOS activity is decreased by glucocorticoids and increased by proinflammatory cytokines. The activation of iNOS generates NO in the measure of up 1000-fold greater than nNOS or eNOS [57] it has also been demonstrated that the more important modulators of these proinflammatory cytokines are the mitogen activated protein kinases [32]. This accelerated NO synthesis has however an opposite effect because

${ }^{*}$ Corresponding author: Prof. Gregorio Caimi, Dipartimento Biomedico di Medicina Interna e Specialistica, Università di Palermo, Via del Vespro, 12990100 Palermo, Italy. Tel.: +39 0916554406; Fax: +39 091 6554535; E-mail: gregorio.caimi@unipa.it. 
NO interacts with the superoxide anion $\left(\mathrm{O}_{2}{ }^{-}\right)$to produce peroxynitrite and other oxidants involved in tissue injury. Considering this pathophysiological aspect, NOS inhibitors have been administrated in some critical conditions, such as congestive heart failure [64], refractory cardiogenic shock [21], cardiogenic shock complicating an acute myocardial infarction [26, 58, 70] and septic shock [44]. Among the NOS inhibitors, the L-monomethylarginine (L-NMM), a non-selective NOS inhibitor, has been investigated the most. The TRIUMPH study [70] has been conducted in 130 centers and in 8 countries in North America and Europe, enrolling 398 patients with acute myocardial infarction (AMI) and cardiogenic shock; it has demonstrated, however, that the use of tilarginine acetate has no effect on mortality of these patients. Other authors [65] have consequently suggested avoiding further trials with non-selective inhibitors of NOS in the cardiovascular area. Whereas the considerations about the possible coming of $\mathrm{NO}$ are interesting. As it is known, $\mathrm{NO}$ metabolites, such as nitrite $\left(\mathrm{NO}_{2}{ }^{-}\right)$and nitrate $\left(\mathrm{NO}_{3}{ }^{-}\right)$, usually evaluated together and expressed as NOx, may play a positive role in stable clinical conditions, because they can be reduced to NO once again $[20,49,53,54]$. All the NO produced, including those generated by red blood cells subjected to several stimuli, such as mechanical and shear stress [71-73], act on the cardiovascular system contributing to the modulation of blood flow and vascular tone and regulating vascular relaxation without, however, recognizing the pivotal role played in this microcirculatory area by the haemorheological pattern $[28,33]$.

Considering these information, we examined the behavior of NOx in different clinical conditions, such as arterial hypertension, chronic kidney disease (CKD) on conservative treatment, metabolic syndrome, obstructive sleep apnea syndrome (OSAS), systemic sclerosis, CKD in dialysis treatment and jouvenile acute myocardial infarction.

\section{Subjects}

We examined 7 groups of subjects.

- The first group included 25 subjects (19 men and 6 women; mean age $44.4 \pm 7.7$ yrs) with untreated mild essential hypertension. In this group hypertension duration was of $19.3 \pm 32.8$ months, fasting blood glucose was $91.4 \pm 10.9 \mathrm{mg} / \mathrm{dl}$, cholesterol level was $210.0 \pm 37.0 \mathrm{mg} / \mathrm{dl}$, HDL-chol was $44.41 \pm 8.19 \mathrm{mg} / \mathrm{dl}$, triglycerides were $101.1 \pm 7.8 \mathrm{mg} / \mathrm{dl}$, and serum uric acid was $5.74 \pm 1.63 \mathrm{mg} / \mathrm{dl}$. In hypertensives the body mass index (BMI) was $26.6 \pm 3.5$ and the waist to hip ratio (WHR) was $0.91 \pm 0.05$, while day-time systolic (S) and diastolic (D) blood pressure (BP) were respectively $133.80 \pm 8.12$ and $86.05 \pm 6.79 \mathrm{mmHg}$, night-time SBP and DBP were respectively $120.40 \pm 10.86$ and $75.00 \pm 7.65 \mathrm{mmHg}$ and the 24-h SBP and DBP were respectively $128.00 \pm 8.50$ and $81.73 \pm 6.36 \mathrm{mmHg}$. This group was compared with a control group including 27 healthy subjects (20 men and 7 momen; mean age $41.3 \pm 6.2 \mathrm{yrs}$ ).

- The second group included 41 subjects (25 men and 16 women; mean age $64.7 \pm 11.1$ yrs) with clinically stable CKD on conservative management. The causes of CKD were chronic pyelonephritis in 9 subjects, nephroangiosclerosis in 6 , chronic pyelonephritis associated with nephroangiosclerosis in 8 , chronic glomerulonephritis in 5, diabetic nephropathy in 8 and polycystic kidney disease in 5 . In this group serum creatinine was $3.05 \pm 1.79 \mathrm{mg} / \mathrm{dl}$, creatinine clearance was $28.56 \pm 17.13 \mathrm{ml} / \mathrm{min}$, haemoglobin level was $12.2 \pm 2.1 \mathrm{~g} / \mathrm{dl}$. The CKD subjects were subdivided according to age in two subgroups: 22 subjects $<65$ yrs and 19 subjects $\geq 65$ yrs. This group was compared with a control group including 51 healthy subjects ( 39 men and 12 momen; age range 24-60 yrs). 
- The third group included 106 subjects (61 men and 45 women; mean age $53.5 \pm 8.9$ yrs) with metabolic syndrome (MS) defined according the International Diabetes Federation (IDF) criteria [3]. In this group BMI was $32.32 \pm 4.53$, waist circumference was $106.7 \pm 11.2 \mathrm{~cm}$, SBP and DBP were respectively $132.1 \pm 16.3$ and $81.2 \pm 99 \mathrm{mmHg}$, fasting blood glucose was $114.3 \pm 44.3 \mathrm{mg} / \mathrm{dl}$, HDLchol was $40.4 \pm 10.8 \mathrm{mg} / \mathrm{dl}$ and triglycerides were $220.2 \pm 147.8 \mathrm{mg} / \mathrm{dl}$. This group was compared with a control group including 54 healthy subjects ( 35 men and 19 momen; mean age $41.3 \pm 7.4 \mathrm{yrs}$ ) recruited from the hospital staff.

- The fourth group included 48 subjects ( 36 men and 12 women; mean age $50.3 \pm 14.68$ yrs) with OSAS. In this group BMI was $35.46 \pm 7.28$, waist circumference was $118.75 \pm 15.88 \mathrm{~cm}$, neck circumference was $44.4 \pm 4.77 \mathrm{~cm}$, and the apnea/hypopnea index (AHI) was $38.47 \pm 25.39$. OSAS subjects were subdivided according to the AHI value in two subgroups: Low (21 subjects with AHI $<30$ ) and High (27 subjects with AHI $>30$ ). This group was compared with a control group including 54 healthy subjects ( 35 men and 19 momen; mean age $41.3 \pm 7.4 \mathrm{yrs}$ ) recruited from the hospital staff.

- The fifth group included 14 women (mean age $45.4 \pm 5.4 \mathrm{yrs}$ ) with systemic sclerosis complicated with Raynaud phenomenon. In these patients the duration of the disease was $3.1 \pm 2.0 \mathrm{yrs}$; each patient showed skin disease, 3 subjects had esophageal disease, 2 subjects had pulmonary alterations and 1 subject showed renal damage. Immunological alterations (ANA, anti-Scl, anti SSA) were demonstrated in 12 women. This group was compared with a control group including 12 healthy women (mean age $35.1 \pm 6.5 \mathrm{yrs}$ ).

- The sixth group included 42 dialyzed subjects ( 21 men and 21 women; mean age $66.83 \pm 14.8$ yrs). The cause of CKD was unknown in 12 subjects, nephroangiosclerosis was demonstrated in 12 , chronic glomerulonephritis in 4, diabetic nephropathy in 10 and polycystic kidney disease in 4. Dialysis vintage in the whole group was $55.3 \pm 43.5$ months. In this group the behavior of NOx was evaluated before and after a standard hemodialysis session. This group was compared with a control group including 51 healthy subjects ( 39 men and 12 momen; age range 24-60 yrs).

- The seventh group included 105 young subjects ( 97 men and 8 women, aged $<46$ yrs) with recent AMI. The mean age was $39.6 \pm 5.5 \mathrm{yrs}$. The time interval between AMI onset and the evaluation of NOx was 13.0 \pm 7.0 days. AMI subjects were subdivided according to the number of risk factors (family history of coronary artery diseases, smoke, hypercholesterolemia, diabetes mellitus, essential hypertension) into 3 subgroups: 38 subjects had 0 to 1 risk factor, 35 had 2 risk factors and 32 had 3 to 5 risk factors. On the basis of coronary angiography (performed only in 92 subjects), AMI subjects were subdivided into 3 subgroups considering the extent of coronary lesions: 21 subjects showed no significant lesions, 1-vessel disease was present in 41 subjects and 2-or 3-vessel disease was observed in 30 subjects. This group was compared with a control group including 51 healthy subjects (39 men and 12 momen; age range 24-60 yrs).

\section{Methods}

On fasting venous blood the NO production was evaluated by a micromethod which measures the concentration of $\mathrm{NO}$ metabolites: nitrite and nitrate (NOx). In vivo NO has a very short life (less than $0.1 \mathrm{sec})$ and it is converted into nitrite $\left(\mathrm{NO}_{2}{ }^{-}\right)$, which has a half-life of few minutes, and into the more stable nitrate $\left(\mathrm{NO}_{3}{ }^{-}\right)$. Then $\mathrm{NOx}$ represents almost only the nitrate concentration. In the laboratory method adopted by us at first nitrate was converted into nitrite by a nitrate reductase and then nitrite was assessed by spectrophotometry after addition of Griess reagent. 


\section{Statistical analysis}

Data were expressed as means \pm S.D.; the difference between normal subjects $(\mathrm{N})$ and each group of patients was evaluated according to the Student's $t$ test for unpaired data. The statistical difference between control subjects and subjects with MS subdivided according to the presence or not of diabetes mellitus was estimated according to the 1-way analysis of variance (ANOVA) integrated with the Bonferroni test. Same statistical approach was used for the examination of OSAS subjects subdivided according to the AHI value and for the examination of AMI subjects, subdivided according to risk factors and extension of coronary lesions. The evaluation of NOx before and after dialysis was effected using the Student's $t$ test for paired data; same approach was employed to evaluate NOx before and after treatment with intravenous iloprost in subjects with systemic sclerosis and to evaluate NOx at the initial stage of AMI and 3 and 12 months later. The correlations were performed employing the linear regression test. The null hypothesis was rejected for $p$ values $<0.05$.

\section{Results}

The obtained data are described for each clinical condition.

\subsection{Arterial hypertension}

In this group of subjects with mild essential hypertension (EH) we observed [15] a significant increase in $\mathrm{NOx}(\mathrm{N}=28.36 \pm 18.36$; $\mathrm{EH}=48.78 \pm 23.17, p<0.001)$. The NOx was not related to metabolic parameters (fasting glucose level, lipid pattern, uric acid, urea, creatinine), to BMI and WHR or to the blood pressure values (day-time, night-time and 24-h systolic and diastolic blood pressure).

\subsection{Chronic kidney disease}

In this group of CKD on conservative treatment we found [12] a significant rise in NOx $(\mathrm{N}=24.38 \pm 15.67 ; \mathrm{CKD}=74.19 \pm 69.05, p<0.001)$. In this group no correlation was noted between NOx, creatinine level and creatinine clearance. The subdivision of these subjects according to age did not show any difference (data not shown).

\subsection{Metabolic syndrome}

In this group of subjects with MS, we observed [13] a significant increment in NOx ( $N=28.07 \pm 18.83$; $\mathrm{MS}=79.82 \pm 29.22, p<0.001$ ). This finding was also present between normal subjects and MS subjects with diabetes mellitus $(\mathrm{N}=28.07 \pm 18.83$; DMS $=78.10 \pm 20.76, p<0.001)$ and between normal subjects and MS subjects without diabetes mellitus $(\mathrm{N}=28.07 \pm 18.83$; NDMS $=80.99 \pm 33.93, p<0.001)$. Testing the linear regression between NOx, age, anthropometric profile, blood pressure values and glycometabolic pattern, we found a positive correlation between NOx and triglycerides $(r=0.344, p<0.001)$ in the whole group of MS subjects, a positive correlation between NOx and total cholesterol $(r=0.442$, $p<0.01)$ and between NOx and LDL-cholesterol $(r=0.441, p<0.01)$ in the subgroup of diabetic subjects $(\mathrm{N}=43)$, and a positive correlation between NOx and triglycerides $(r=0.43, p<0.001)$ while a negative correlation between NOx and HDL-cholesterol $(r=-0.287, p<0.05)$ in the subgroup of nondiabetic subjects $(\mathrm{N}=63)$. 


\subsection{OSAS}

In this group of subjects no statistical difference in NOx was observed in comparison with normal controls $(\mathrm{N}=28.07 \pm 18.83$; OSAS $=27.49 \pm 10.13)$. However, subdividing the whole group of OSAS according to AHI value in two subgroups (Low: AHI <30, High: AHI $>30$ ), we noted a slight decrease of NOx in the subgroup with AHI $>30$ in comparison with the subgroup with AHI $<30(\mathrm{H}=22.84 \pm 7.64$; $\mathrm{L}=33.47 \pm 10.05, p<0.05$ ), but not with normal controls. We found a negative correlation between NOx and AHI in the whole group of OSAS subjects $(r=-0.615, p<0.001)$, in the subgroup with low AHI $(r=-0.490, p<0.05)$ and also in the subgroup with high AHI $(r=-0.413, p<0.05)$.

\subsection{Systemic sclerosis}

In this group of subjects with systemic sclerosis (SS) complicated by Raynaud phenomenon, we observed [47] a slight increase in NOx $(\mathrm{N}=23.26 \pm 16.11$; $\mathrm{SS}=37.77 \pm 18.46, p<0.05)$. After a short treatment with intravenous iloprost ( 0.5 to $2 \mathrm{ng} / \mathrm{kg} / \mathrm{min}, 6$ hours/die for 5 consecutive days and, after an interval of 2 days, for another 5 consecutive days) we noted a marked increase in NOx concentration (before iloprost $=37.77 \pm 18.46$; after iloprost $=61.19 \pm 28.79, p<0.05$ ).

\subsection{Dialyzed subjects}

In this group of dialyzed subjects (DS) we found $[11,45]$ a significant increase in NOx $(\mathrm{N}=24.38 \pm 15$; $\mathrm{DS}=69.20 \pm 35.33, p<0.001$ ). The subdivision of DS according to dialysis vintage did not show any difference in NOx concentration (data not shown). The trend of NOx before and after a standard hemodialysis session showed instead a significant decrease of this parameter (before $=69.20 \pm 35.33$; after $=26.80 \pm 17.80, p<0.001$ ). During the dialysis session, the employment of different filters did not influence the NOx behavior (data not shown).

\subsection{Acute myocardial infarction}

In this group of young subjects with AMI we found [46] a significant increase in NOx $(\mathrm{N}=24.38 \pm 15.67 ; \mathrm{AMI}=64.47 \pm 31.90, p<0.001)$. Subdividing AMI subjects into smokers and nonsmokers, we noted that NOx was significantly lower in nonsmokers (smokers $=70.91 \pm 33.38$; nonsmokers $=50.85 \pm 15.31, p<0.05$ ). Subdividing AMI subjects according to the number of risk factors or of stenosed coronary vessels, no significant difference in NOx concentration between the subgroups was observed. In 55 AMI subjects NOx was evaluated at the initial stage and after 12 months and it showed a significant decrease (initial stage $=69.33 \pm 27.38 ; 12$ months $=37.71 \pm 17.29, p<0.001$ ). In a small group of AMI subjects (38 men and 5 women) we evaluated [14] the trend of NOx at the initial stage (T1), after 3 months (T2) and after 12 months (T3) observing its progressive decrease (T1 $=70.14 \pm 26.70$, $\mathrm{T} 2=56.70 \pm 23.87, \mathrm{~T} 3=37.27 \pm 18.96)$.

\section{Conclusive consideration}

Our finding on mild essential hypertension points out a significant NOx increase. As in this clinical condition several inflammatory molecules seem to be released, this datum might be related to a NO 
overproduction by macrophages through iNOS activation. However, it must be underlined that this finding, that is in agreement with those of few authors $[60,79]$, conflicts with the observations of others $[6,38$, $39,74]$. Considering this latter remark, it is not possible to exclude, as far as the NOx concentration is concerned, the role played in this cardiovascular disease by impaired microvascular function, that can later progress into capillary rarefaction, as has been clearly demonstrated previously by several studies $[19,22,27,37]$. This microvascular alteration perhaps is not present in subjects with mild essential hypertension.

The findings observed in CKD on conservative treatment and in dialyzed subjects need to be examined together. In these two groups, in fact, the increase in NOx, described also by other authors [36], may be explained by impairment of renal excretion [50] or by macrophage NO synthesis. This latter hypothesis deserves to be underlined considering the role played by asymmetric dimethylarginine (ADMA) in CKD [10]. As it is known, in fact, ADMA removal is blocked in CKD subjects leading to high plasma levels of this inhibitor of all NOS isoforms [48]. Regarding the trend of NOx before and after dialysis session, we observed a significant decrease in NOx after dialysis as did other authors [78], although Zhang et al. have found a NOx increase [80]. This discrepancy regarding the trend of NOx after dialysis must be further developed.

In MS subjects a NOx increase was observed and this finding was similar in the two subgroups of diabetic and nondiabetic subjects. These data agree with the observations of othes who studied NOx in MS or in its components $[7,8,15,17,35,36,60,62,63,79]$. Our results show in diabetic MS subjects a positive correlation between NOx and total cholesterol and LDL-cholesterol while in nondiabetic subjects a negative correlation between NOx and HDL-cholesterol. The literary data do not confirm these findings in healthy adult subjects [31] or in overweight and obese women [59] while in adolescents NOx has been correlated positively to the total cholesterol and LDL-cholesterol and negatively to HDLcholesterol [18]. We observed a positive correlation between NOx and triglycerides in the entire group of MS subjects and in the subgroup of nondiabetics. This datum, in agreement with those described by others in postmenopausal MS women [16], in adolescents [18] and in a general healthy population [31], is different from that observed [24] in subjects with normal-weight obese syndrome.

The behavior of NOx in subjects with OSAS is interesting. This is confirmed by some authors [23], but conflicts with other papers $[40,66]$; the subdivision of these subjects according to AHI shows a marked decrease in NOx in the subgroup with AHI $>30$. Agreeing with other authors [30], in the entire group and in the two subgroups of OSAS we found a negative correlation between NOx and AHI. Another interesting finding is the positive correlation between AHI and neck circumference observed in entire group $(r=0.60, p<0.001)$ and in the subgroup with AHI $<30(r=0.55, p<0.05)$. Later we will examine, especially in OSAS subjects with AHI $>30$, the trend of NOx after treatment with continuous positive airway pressure (cPAP); some papers have in fact described a NOx increase after therapy with cPAP [40, $61,66]$, differently from others [23].

In subjects with systemic sclerosis complicated by Raynaud's phenomenon we observed a NOx increase and this datum is entirely in agreement with those of some authors $[25,55,69,77]$ but partially with those of others who described only a nitrite $\left(\mathrm{NO}_{2}{ }^{-}\right)$increase [61] or a nitrate increase $\left(\mathrm{NO}_{3}{ }^{-}\right)$[5]. Other authors $[4,52]$ however, found a NOx decrease in this clinical condition. In the paper of Takagi et al [69] NOx level was positively correlated with some clinical features, such as the extent of skin fibrosis, short disease duration and active fibrosing alveolitis. In a subgroup of subjects with systemic sclerosis examined by Mok et al [55] a positive correlation between NOx and pulmonary arterial pressure was found and prednisolone treatment was associated with decreased NOx. In our small group of subjects with systemic sclerosis the venous infusion of iloprost increases significantly the value of NOx. This 
finding is different from that observed by others [51] in 29 subjects with chronic peripheral ischaemia (15 suffering from systemic sclerosis); in this group in fact iloprost infusion enhances microvascular function with clinical benefits but without any NOx variation.

In young subjects with AMI we found a marked increase in NOx, in agreement with other authors [68]. As it is known, during the acute phase of AMI, iNOS activity increases as a reaction to the high oxidative stress [76]. In experimental models the ligation of the left anterior descending coronary artery was associated with NOx increase, which reached a peak after 3 days [2]. The same behavior of NOx has been observed in a small group of subjects with anterior myocardial infarction examined at 24, 48 and 72 hours after the event [1]. In this research the NOx peak occurred 2 or 3 days after the onset of symptoms, suggesting that NOx increase was correlated with iNOS activation induced especially by cytokines. In our study $[14,46]$ NOx was significantly reduced in nonsmokers and that its trend was conditioned more by cardiovascular risk factors than by the extent of coronary lesions. At 3 and 12 months we observed a progressive decrease of NOx, remaining at both times significantly higher than the control group. The persistent increase in NOx could be a further confirmation of a chronic inflammatory state, that might be related to the genetic profile of these subjects, showing in many cases pro-inflammatory alleles [9, 34, 41-43].

In conclusion, the data described seem to point out a role of iNOS activation in almost all the clinical conditions considered. The iNOS activity is stimulated in particular by pro-inflammatory cytokines and by oxidative stress, which is evident in each group of patients studied by us as increased lipid peroxidation and protein oxidation and decreased total antioxidant status. Then it is possible to suppose that the NOx increase found in arterial hypertension, chronic kidney disease, metabolic syndrome, systemic sclerosis and juvenile myocardial infarction can reflect this hyperactivation. Whereas the behavior of NOx in OSAS subjects needs further investigation. Its trend, in fact, depends on OSAS severity expressed as AHI. The subdivision of OSAS subjects according to this index allows the discrimination of two subgroups and the demonstration that in the subgroup with AHI $>30$ the NOx value is significantly lower than in the subgroup with $\mathrm{AHI}<30$. It is not possible to exclude that this behavior might depend, through the nocturnal hypoxemia, on the altered balance between NOx synthesis and NOx removal and this hypothesis seems to be supported by the increase in NOx value after cPAP therapy.

\section{References}

[1] K. Akiyama, A. Kimura, H. Suzuki, Y. Takeyama, T.L. Gluckman, A. Terhakopian, T. Katagiri, K.Y. Suh, J. Roseto and R.J. Ring, Production of oxidative products of nitric oxide in infarcted human heart, Journal of Molecular and Cellular Cardiology 32 (1998), 373-379.

[2] K. Akiyama, H. Suzuki, P. Grant and R.J. Bing, Oxidant products of nitric oxide, NO2 and NO3, in plasma after experimental myocardial infarction, Journal of Molecular and Cellular Cardiology 29 (1997), 1-9.

[3] K.G. Alberti, P. Zimmet and J. Shaw, Metabolic syndrome - a new world-wide definition. A Consensus Statement from the International Diabetes Federation, Diabetic Medicine 23 (2006), 469-480.

[4] Y. Allanore, D. Borderie, P. Hilliguin, A. Nernvann, M. Levacher, H. Lemarechal, O.G. Ekindjian and A. Kahan, Low levels of nitric oxide (NO) in systemic sclerosis: Inducible NO synthase production is decreased in cultured peripheral blood monocyte/macrophage cells, Rheumatology (Oxford) 40 (2001), 1089-1096.

[5] G.N. Andersen, K. Caidahl, E. Kazzam, A.S. Petersson, A. Waldenstrom, L. Mincheva-Nilsson and S. Rantapaa-Dahlqvist, Correlation between increased nitric oxide production and markers of endothelial activation in systemic sclerosis, Arthritis \& Reumatism 43 (2000), 1085-1093.

[6] M.C. Armas-Padilla, M.J. Armas-Hernandez, B. Sosa-Chanache, R. Cammarata, B. Pacheco, J. Guerrero, A.R. CArvajal, R. Hernandez-Hernandez, Z.H. Israili and M. Valasco, Nitric oxide and malonildialdehyde, American Journal of Therapeutics 14 (2007), 172-176. 
[7] S.Z. Asl, A. Ghasemi and F. Azizi, Serum nitric oxide metabolites in subjects with metabolic syndrome, Clinical Biochemistry 41 (2008), 1342-1347.

[8] A. Aydin, H. Orhan, A. Sayal, M. Ozata, G. Sahin and A. Isimer, Oxidative stress and nitric oxide related parameters in type II diabetes mellitus: Effects of glycemic control, Clinical Biochemistry 34 (2001), 65-70.

[9] C.R. Balistreri, S. Vasto, F. Listí, M.P. Grimaldi, D. Lio, G. Colonna-Romano, M. Caruso, G. Caimi, E. Hoffman, C. Caruso and G. Candore, Association between $+1059 \mathrm{G} / \mathrm{C}$ CRP polymorphism and acute myocardial infarction in a cohort of patients from Sicily: A pilot study, Annals of the New York Academy of Science 1067 (2006), 267-281.

[10] R.H. Boger and C. Zoccali, ADMA: A novel risk factor that explains excess cardiovascular event rate in patients with end-stage renal disease, Atherosclerosis 4 (2003), 23-28.

[11] G. Caimi, C. Carollo, M. Montana, R. Iatrino, B. Bondí and R. Lo Presti, Nitric oxide metabolites, leukocyte activation markers and oxidative status in dialyzed subjects, Blood Purification 27 (2009), 194-198.

[12] G. Caimi, C. Carollo, M. Montana, F. Vaccaro and R. Lo Presti, Elastase, myeloperoxidase, nitric oxide metabolites and oxidative status in subjects with clinical stable chronic renal failure on conservative treatment, Clin Hemorheol Microcirc 43 (2009), 251-256.

[13] G. Caimi, E. Hopps, M. Montana, D. Noto, B. Canino, R. Lo Presti and M.R. Averna, Evaluation of nitric oxide metabolites in a group of subjects with metabolic syndrome, Diabetes \& Metabolic Syndrome 6 (2012), 132-135.

[14] G. Caimi, M. Montana, V. Calandrino, M. Caruso, C. Carollo, A. Catania and R. Lo Presti, Nitric oxide metabolites (nitrite and nitrate) in young patients with recent acute myocardial infarction, Clin Hemorheol Microcirc 40 (2008), 157-163.

[15] G. Caimi, G. Mulè, E. Hopps, C. Carollo and R. Lo Presti, Nitric oxide metabolites and oxidative stress in mild essential hypertension, Clin Hemorheol Microcirc 46 (2010), 321-325.

[16] P. Chedraui, G.S. Escobar, C. Ramırez, F.R. Perez-Lopez, L. Hidalgo, P. Mannella, A. Genazani and T. Simoncini, Nitric oxide and pro-inflammatory cytokine serum levels in postmenopausal women with the metabolic syndrome, Gynecological Endocrinology 28 (2012), 787-791.

[17] W.Y. Chien, K.D. Yang, H.L. Eng, Y.H. Hu, P.Y. Lee, S.T. Wang and P.W. Wang, Increased plasma concentration of nitric oxide in type 2 diabetes but not in nondiabetic individuals with insulin resistance, Diabetes \& Metabolism 31 (2005), 63-68.

[18] J.W. Choi, Enhanced nitric oxide production is closely associated with serum lipid concentrations in adolescents, Clinica Chimica Acta 347 (2004), 151-156.

[19] G. Ciuffetti, L. Pasqualini, M. Pirro, R. Lombardini, M. de SIO, G. Schillaci and E. Mannarino, Blood rheology in men with essential hypertension and capillary rarefaction, Journal of Human Hypertension 16 (2002), 533-537.

[20] K. Cosby, K.S. Partovi, J.H. Crawford, R.P. Patel, C.D. Reiter, S. Martyr, B.K. Yang, M.A. Waclawiw, G. Zalos, X. Xu, K.T. Huang, H. Shields, D.B. Kim-Shapiro, A.N. Schecher, R.O. Cannon 3rd and M.T. Gladwin, Nitrite reduction to nitric oxide by deoxyhemoglobin vasodilates the human circulation, Nature Medicine 9 (2003), 1498-1505.

[21] G. Cotter, E. Kaluski, O. Milo, A. Blatt, A. Salah, A. Hendler, R. Krakover, A. Golick and Z. Vered, LINCS: L-NAME (a NO synthase inhibitor) in the treatment of refractory cardiogenic shock, European Heart Journal 24 (2003), 1287-1295.

[22] R.T. de Jong, E.H. Sernè, R.G. Ijzerman, G. de Vries and C.D.A. Stehouwer, Impaired microvascular function in Obesity, Circulation 109 (2004), 2529-2535.

[23] M. Del Ben, M. Fabiani, L. Loffredo, L. Polimeni, R. Carnevale, F. Baratta, M. Brunori, F. Albanese, T. Augelletti, F. Violi and F. Angelico, Oxidative stress mediated arterial dysfunction in patients with obstructive sleep apnoea and the effect of continuous positive airway pressure treatment, BMC Pulmonary Medicine 12 (2012), 36.

[24] L. Di Renzo, F. Galvano, C. Orlandi, A. Bianchi, C. Di Giacomo, L. La Fauci, R. Acquaviva and A. De Lorenzo, Oxidative stress in normal-weight obese syndrome, Obesity 18 (2010), 2125-2130.

[25] A. Dooley, B. Gao, N. Bradley, D.J. Abraham, C.M. Black, M. Jacobs and K.R. Burkdorfer, Abnormal nitric oxide metabolism in systemic sclerosis: Increased levels of nitrated proteins and asymmetric dimethylarginine, Rheumatology (Oxford) 45 (2006), 676-684.

[26] V. Dzavik, G. Cotter, H.R. Reynolds, J.H. Alexander, K. Ramanathan, A.L. Stebbins, D. Hathaway, M.E. Farkouh, E.M. Ohman, D.A. Baran, R. Prondzinsky, J.A. Panza, W.J. Cantor, Z. Vered, C.E. Buller, N.S. Kleiman, J.G. Webb, D.R. Holmes, J.E. Parrillo, S.L. Hazen, S.S. Gross, R.A. Harrington and J.S. Hochman, Effect of nitric oxide synthase inhibition on haemodynamics and outcome of patients with persistent cardiogenic shock complicating acute myocardial infarction: A phase II dose-ranging study, European Heart Journal 28 (2007), 1109-1116.

[27] B. Fagrell, Microcirculatory methods for the clinical assessment of hypertension, hypotension and ischemia, Annals of Biomedical Engineering 14 (1986), 163-173.

[28] S. Forconi and T. Gori, Endothelium and hemorheology, Clin Hemorheol Microcirc 53 (2013), 3-10. 
[29] U. Forstermann, H. Kleinert, I. Gath, P. Schwarz, E.I. Closs and N.J. Dun, Expression and expressional control of nitric oxide synthases in various cell types, Advances in Pharmacology 34 (1995), 171-186.

[30] C.M. Franco, A.M. Lima, L. Ataide Jr., O.G. Lins, C.M. Castro, A.A. Bezerra, M.F. de Oliveira and J.R. Oliveira, Obstructive sleep apnea severity correlates with cellular and plasma oxidative stress parameters and affective symptoms, Journal of Molecular Neuroscience 47 (2012), 300-310.

[31] A. Ghasemi, S. Zahedi Asl, Y. Mehrabi, N. Saadat and F. Azizi, Serum nitric oxide metabolite levels in a general healthy population: Relation to sex and age, Life Sciences 83 (2008), 326-331.

[32] R. Ginnan, B.J. Guikema, K.E. Halligan, H.A. Singer and D. Jourd'heuil, Regulation of smooth muscle by inducible nitric oxide synthase and NADPH oxidase in vascular proliferative diseases, Free Radical Biology and Medicine 44 (2008), $1232-1245$

[33] T. Gori, A. Damaske, S. Muxel, M.C. Radmacher, F. Fasola, S. Schaefer, M. Fineschi, S. Forconi, F. Jung, T. Munzel and J.D. Parker, Endothelial function and hemorheological parameters modulate coronary blood flow in patients without significant coronary artery disease, Clin Hemorheol Microcirc 52 (2012), 255-266.

[34] M.P. Grimaldi, G. Candore, S. Vasto, M. Caruso, G. Caimi, E. Hoffman, G. Colonna-Romano, D. Lio, Y. Shinar, C. Franceschi and C. Caruso, Role of the pyrin M694V (A2080G) allele in acute myocardial infarction and longevity: A study in the Sicilian population, Journal of Leukocyte Biology 79 (2006), 611-615.

[35] H. Higashino, H. Miya, H. Mukai and Y. Miya, Serum nitric oxide metabolite (NOx) levels in hypertensive patients at rest: A comparison of age, gender, blood pressure and complications using normotensive controls, Clinical and Experimental Pharmacology and Physiology 34 (2007), 725-731.

[36] H. Higashino, M. Tabuchi, S. Yamagata, T. Kurita, H. Miya, H. Mukai and Y. Miya, Serum nitric oxide metabolite levels in groups of patients with various diseases in comparison of healthy control subjects, Journal of Medical Sciences 10 (2010), $1-11$.

[37] F. Jung, W. Kolepke, S. Spitzer, H. Kiesewetter, K.W. Ruprecht, R. Bach, H. Schieffer and E. Wenzel, Primary and secondary microcirculatory disorders in essential hypertension, Clinical Investigation 71 (1993), 132-138.

[38] K. Kedziora-Kornatowska, J. Czuczejko, H. Pawluk, T. Kornatowski, J. Motyl, L. Szadujkis-Szadurski, K. Szewczyk-Golec and J. Kedziora, The markers of oxidative stress and activity of the antioxidant system in the blood of elderly patients with essential arterial hypertension, Cellular and Molecular Biology Letters 9 (2004), 635-641.

[39] C.A. Kumar and U.N. Das, Lipid peroxides, anti-oxidants and nitric oxide in patients with pre-eclampsia and essential hypertension, Medical Science Monitor 6 (2000), 901-907.

[40] L. Lavie, A. Hefetz, R. Luboshitzky and O. Lavie, Plasma levels of nitric oxide and L-arginine in sleep apnea patients, Journal of Molecular Neuroscience 21 (2003), 57-63.

[41] D. Lio, G. Candore, A. Crivello, L. Scola, G. Colonna-Romano, L. Cavallone, E. Hoffman, M. Caruso, F. Licastro, C.M. Caldarera, A. Branzi, C. Franceschi and C. Caruso, Opposite effects of interleukin 10 common gene polymorphism in cardiovascular diseases and in successful ageing: Genetic background of male centenarians is protective against coronary heart disease, Journal of Medical Genetics 41 (2004), 790-794.

[42] F. Listí, G. Candore, D. Lio, L. Cavallone, G. Colonna-Romano, M. Caruso, E. Hoffman and C. Caruso, Association between platelet endothelial cellular adhesion molecule 1 (PECAM-1/CD31) polymorphism and acute myocardial infarction: A study in patients from Sicily, European Journal of Immunogenetics 31 (2004), 175-178.

[43] F. Listí, G. Candore, D. Lio, M. Russo, G. Colonna-Romano, M. Caruso, E. Hoffman and C. Caruso, Association between C1019T polymorphism of connexyn37 and acute myocardial infarction: A study in patients from Sicily, International Journal of Cardiology 102 (2005), 269-271.

[44] A. Lopez, A.L. Lorente, J. Steingrub, J. Bakker, A. McLuckie, S. Willatts, M. Brockway, A. Anzueto, L. Holzapfel, D. Breen, M.S. Silverman, J. Takala, J. Donaldson, C. Aneson, G. Grove, S. Grossman and R. Grover, Multiple-center, randomized, placebo-controlled, double-blind study of the nitric oxide synthase inhibitor 546C88: Effect on survival in patients with septic shock, Critical Care Medicine 32 (2004), 21-30.

[45] R. Lo Presti, C. Carollo, M. Montana, F. Vaccaro and G. Caimi, Nitric oxide metabolites in chronic renal failure in conservative and in hemodialysis treatment, Trace Elements and Electrolites 25 (2008), 211-212.

[46] R. Lo Presti, A. Catania, T. D'Amico, M. Montana, M. Caruso and G. Caimi, Oxidative stress in young subjects with acute myocardial infarction: Evaluation at the initial stage and after 12 months, Clinical and Applied Thrombosis and Hemostasis 14 (2008), 421-427.

[47] R. Lo Presti, G. Milio, D. Lucido, G. Amodeo, C. Carollo and G. Caimi, Stress ossidativo in pazienti con sclerodermia: Effetti dell'iloprost, Minerva Cardioangiologica 55 (2007), 179-180. 
[48] C.M. Loughrey, I.S. Young, J.H. Lightbody, D. McMaster, P.T. McNamee and E.R. Trimble, Oxidative stress in haemodialysis, Quarterly Journal of Medicine 87 (1994), 679-683.

[49] J.O. Lundberg and M. Govoni, Inorganic nitrate is a possible source for systemic generation of nitric oxide, Free Radical Biology and Medicine 37 (2004), 395-400.

[50] I.M.J. Mackenzie, A. Ekangaki, J.D. Young and C.S. Garrard, Effect of renal function on serum nitrogen oxide concentration, Clinical Chemistry 42 (1996), 440-444.

[51] A. Mazzone, C. Cusa, L. Bucci, M. Vezzoli, S. Ghio, I. Buggia, M.B. Regazzi, G. Fossati, I. Mazzucchelli and D. Gritti, The effect of iloprost infusion on microcirculation is independent of nitric oxide metabolites and endothelin-1 in chronic peripheral ischemia, European Journal of Clinical Investigation 29 (1999), 1-5.

[52] C.J. Menkes, Y. Allanore, D. Borderie, P. Hilliquin, A. Hernvann, O. Ekindjian and A. Kahan, Inducible nitric oxide synthase expression and nitric oxide production by monocytes in systemic sclerosis, Bulletin de l'Academie Nationale de Medicine 185 (2001), 509-522.

[53] T.M. Millar, C.R. Stevens, N. Benjamin, R. Eisenthal, R. Harrison and D.R. Blake, Xanthine oxidoreductase catalyses the reduction of nitrates and nitrite to nitric oxide under hypoxic conditions, FEBS Letters 427 (1998), 225-228.

[54] A. Modin, H. Björne, M. Herulf, K. Alving, E. Weitzberg and J.O. Lundberg, Nitrite derived nitric oxide: A possible mediator of 'acidic-metabolic' vasodilation, Acta Physiologica Scandinavica 171 (2001), 9-16.

[55] M.Y. Mok, P.C.W. Fung, C. Ooi, H.F. Tse, Y. Wong, Y.M. Lam, W.S. Wong and C.S. Lau, Serum nitric oxide metabolites and disease activity in patients with systemic sclerosis, Clinical Rheumatology 27 (2008), 315-322.

[56] S. Moncada, R.M.J. Palmer and E.A. Higgs, Nitric oxide: Physiology, pathophysiology and pharmacology, Pharmacological Reviews 43 (1991), 109-142.

[57] C. Nathan, Inducible nitric oxide synthase: What difference does it make? Journal of Clinical Investigation 100 (1997), $2417-2423$

[58] S.J. Nicholls, Z. Wang, R. Koeth, B. Levison, B. Del Fraino, V. Dzavik, O.W. Griffith, D. Hathaway, J.A. Panza, S.E. Nissen, J.S. Hochman and S.L. Hazen, Metabolic profiling of arginine and nitric oxide pathways predicts hemodynamic abnormalities and mortality in patients with cardiogenic shock after acute myocardial infarction, Circulation 116 (2007), 2315-2324.

[59] M. Olszanecka-Glinianowicz, B. Zahorska-Markiewicz, J. Janowska and A. Zurakowski, Serum concentration of nitric oxide, tumor necrosis factor (TNF)-a and TNF soluble receptors in women overweight and obesity, Metabolism Clinical and Experimental 10 (2004), 1268-1273.

[60] S.M. Ouvina, R.D. La Greca, N.L. Zanaro, L. Palmer and B. Sassetti, Endothelial dysfunction, nitric oxide and platelet activation in hypertensive and dyabetic type II patients, Thrombosis Research 102 (2001), 107-114.

[61] J. Oyama, H. Yamamoto, T. Maeda, A. Ito, K. Node and N. Makino, Continuous positive airway pressure therapy improves vascular dysfunction and decreases oxidative stress in patients with the metabolic syndrome and obstructive sleep apnea syndrome, Clinical Cardiology 35 (2011), 231-236.

[62] S. Ozden, S. Tatlipinar, N. Bicer, V. Yaylali, C. Yildirim, D. Ozbay and G. Guner, Basal serum nitric oxide levels in patients with type 2 diabetes mellitus and different stages of retinopathy, Canadian Journal of Ophthalmology 38 (2003), 393-396.

[63] F.O. Pereira, T.S. Frode and Y.S. Medeiros, Evaluation of tumor necrosis alpha, interleukin-2, soluble receptor, nitric oxide metabolites, and lipid as inflammatory markers in type 2 diabetes mellitus, Mediators of Inflammation 2006 (2006), 39062.

[64] M. Saitoh, T. Osanai, T. Kamada, T. Matsunaga, H. Ishizaka, H. Hanada and K. Okumura, High plasma level of asymmetric dimethylarginine in patients with acutely exacerbated congestive heart failure: Role in reduction of plasma nitric oxide level, Heart Vessels 18 (2003), 177-182.

[65] R. Salem and A. Mebazaa, Nitric oxide inhibition rapidly increases blood pressure with no change in outcome in cardiogenic shock: The TRIUMPH trial, Critical Care 11 (2007), 136-137.

[66] R. Schulz, D. Schmidt, X. Lopes-Ribeiro, C. Lucke, K. Mayer, H. Olschewski, W. Seeger and F. Grimminger, Decrease plasma levels of nitric oxide deirvatives in obstructive sleep apnoea: Response to cPAP therapy, Thorax 55 (2000), 1046-1051.

[67] A. Sud, M. Khullar, A. Wanchu and P. Bambery, Increased nitric oxide production in patients with systemic sclerosis, Nitric Oxide 4 (2000), 615-619.

[68] R.H. Surekha, B.B.M.V. Srikanth, P. Jharna, R.V. Ramachandra, R.V. Dayasagar and A. Jyothy, Oxidative stress and total antioxidant status in myocardial infarction, Singapore Medicine 48 (2007), 137-142.

[69] K. Takagi, Y. Kawaguchi, M. Hara, T. Sugiura, M. Harigai and N. Kamatani, Serum nitric oxide (NO) levels in systemic sclerosis patients: Correlation between NO levels and clinical features, Clinical and Experimental Immunology 134 (2003), 538-544. 
[70] The Triumph Writing Committee, Effect of tilarginine acetate in patients with acute myocardial infarction and cardiogenic shock. The TRIUMPH randomized controlled trial, JAMA 297 (2007), 1657-1666.

[71] P. Ulker, F. Gunduz, H.J. Meiselman and O.K. Baskurt, Nitric oxide generated by red blood cells following exposure to shear stress dilates isolated small mesenteric arteries under hypoxic condition, Clinical Hemorheology and Microcirculation, in press.

[72] P. Ulker, L. Sati, C. Celik-Ozenci, H.J. Meiselman and O.K. Baskurt, Mechanical stimulation of nitric oxide sunthesizing mechanisms in erythrocytes, Biorheology 46 (2009), 121-132.

[73] P. Ulker, N. Yaras, O. Yalcin, C. Celik-Ozenci, P.C. Johnson, H.J. Meiselman and O.K. Baskurt, Shear stress activation of nitric oxide synthase and increased nitric oxide levels in human red blood cell, Nitric Oxide-Biology and Chemistry 24 (2011), 184-191.

[74] T. Vyzantiadis, A. Karagiannis, S. Douma, P. Harsoulis, A. Vyzantiadis and C. Zamboulis, Vascular endothelial growth factor and nitric oxide serum levels in arterial hypertension, Clinical and Experimental Hypertension 28 (2006), 603-609.

[75] J.B. Weinberg, Nitric oxide production and nitric oxide syntases type 2 expression by human mononuclear phagocytes a review, Molecular Medicine 4 (1998), 557-591.

[76] S.M. Wildhirt, R.R. Dudek, H. Suzuki, and R.J. Bing, Involvement of inducible nitric oxide synthase in the inflammatory process of myocardial infarction, International Journal of Cardiology 50 (1995), 253-261.

[77] T. Yamamoto, I. Katayama and K. Nishioka, Nitric oxide production and inducible nitric oxide synthase expression in systemic sclerosis, Journal of Rheumatology 25 (1998), 314-317.

[78] J.W. Yoon, M.V. Pahl and N.D. Vaziri, Spontaneous leukocyte activation and oxygen-free radical generation in end-stage renal disease, Kidney International 71 (2007), 167-172.

[79] I. Zavaroni, D. Ardigo, P.C. Rossi, A. Zuccarelli, E. Pacetti, L. Monti, P.M. Piatti and G.M. Reaven, Relationship between plasma nitric oxide concentration and insulin resistance in essential hypertension, American Journal of Hypertension 17 (2004), 549-552.

[80] D.L. Zhang, H. Liao, Y.Y. Wei, Y. Zhang, Q.D. Zhang and Z.G. Wang, Elevation in serum apelin-13 is positively correlated with ADMA in patients on maintenance hemodialysis, Clinical Nephrology 71 (2009), 405-412. 